\title{
A COMBINED USE OF FDM AND DOE METHOD TO DERIVE A NEW TRANSIENT SIMPLIFIED SEMI-ANALYTICAL MODEL: A CASE STUDY OF ANHYDRITE RADIANT SLAB
}

\author{
Abdelatif Merabtine ${ }^{1,2, *}$, Abdelhamid Kheiri $^{3}$, and Salim Mokraoui ${ }^{4}$ \\ ${ }^{1}$ EPF School of Engineering, 2 rue Fernand Sastre, 10430, Rosières-Prés-Troyes, France \\ ${ }^{2}$ ITHEMM, EA 7548, Université de Reims Champagne-Ardenne, Campus Moulin de la Housse, 51687, Reims Cedex, France \\ ${ }^{3}$ LEMTA, CNRS, Université de Lorraine, Nancy, France \\ ${ }^{4}$ College of Engineering, King Saud University Riyadh, Saudi Arabia
}

\begin{abstract}
Radiant floor heating systems (FHS) are considered as reliable heating systems since they ensure maintaining inside air temperature and reduce its fluctuations more efficiently than conventional heating systems. The presented study investigates the dynamic thermal response of an experimental FHS equipped with an anhydrite radiant slab. A new simplified model based on an analytical correlation is proposed to evaluate the heating radiant slab surface temperature and examine its thermal behavior under dynamic conditions. In order the validate the developed analytical model, an experimental scenario, under transient conditions, was performed in a monitored full-scale test cell. 2D and 3D numerical models were also developed to evaluate the accuracy of the analytical model. The method of Design of Experiments (DoE) was used to both derive meta-models, to analytically estimate the surface temperature, and perform a sensitivity study.
\end{abstract}

\section{Introduction}

Optimizing the building sector energy consumption has become a matter of extreme priority ensured through several types of enhancement measures who must consider thermal comfort conditions inside the building. Furthermore, for commercial buildings, inside thermal comfort conditions are maintained basically through Heating, Ventilation and Air Conditioning (HVAC) systems, where their energy consumption account for more than $60 \%$ of the total consumption. Therefore, this high dependency on such system in order to maintain thermal comfort conditions inside a building has drawn the attention of countless research studies aiming at maximizing the efficiency of such systems while lowering the rate of electricity consumption.

In this context, floor heating systems (FHS) has been the subject of several studies focusing on analyzing their effect on inside comfort conditions [1], determining the factors that are influencing their performance [2] as well as predicting their dynamic performance under different conditions in order to adapt a more efficient functioning mode of such systems [3]. The main advantage of the FHS is their ability to maintain comfortable inside air temperature degree varying between $22-26^{\circ} \mathrm{C}$ for the summer season and $21-24^{\circ} \mathrm{C}$ for the winter season regardless of the internal loads and external climates [4]. Furthermore, for the case of radiant heating floors it is essential to keep the floor surface temperature within a range of $27^{\circ} \mathrm{C}$ to $29^{\circ} \mathrm{C}$ in order to not reach overheating conditions [5].

The FHS thermal behavior modeling has been an ongoing research topic for a number of years ([4], [6], [7], [8], [9] [10]). Analytical, numerical, and simplified-model approaches have been used for this purpose. Analytical models ([11], [12], [13], [14]) use a detailed mathematical description of the heat transfer process. The purpose is to derive the critical parameters, such as the surface temperature and the heat flow rate. However, the analytical approach is less used because of the complexity of solving two-dimensional (2D) and three-dimensional (3D) heat transfer problems under transient conditions. However, simplified semi-analytical models, that used a hybrid numerical-analytical method, appear more favorable than analytical or numerical approaches as they allow for a quicker evaluation of the thermal behavior of the FHS, which can help to establish optimal design parameters in the early stages of the heating system design.

The aim of this work is to fill the gap sensed in the existing state of the art through providing a valid and simplified calculation model of the heating anhydrite slab thermal behavior considering all primary design parameters. The design of experiments (DoE) method is used in conjunction with the experimental data obtained for the floor heating surface temperature and a 2D finite

\footnotetext{
"Corresponding author: abdelatif.merabtine@epf.fr
} 
difference model is developed and validated. The overall objective is to help designers to a better conception and optimization of such systems.

\section{Full-scale experiments and data collection}

As shown in Figure 1, the test cell facility is composed of two climatic chambers with an overall area of $11 \mathrm{~m}^{2}$ and a height of $2.1 \mathrm{~m}$. The left chamber, called inside zone, is equipped with a floor heating system comprising $51 \mathrm{~m}$ of embedded cross-linked polyethylene tube placed under an anhydrite screed slab of $5 \mathrm{~cm}$ of thickness, and above 6 $\mathrm{cm}$ of an insulation layer essentially made from wood fibers. The main purpose of this climatic chamber is to reproduce conditions of a warm heated inside environment by means of the radiant heating floor usage.

On the other side, the chamber in the right side, called outside zone, is equipped with a powerful cooler capable of reproducing cold weather conditions. It must be noted that both cells of the test facility are equipped with different HVAC systems and the majority of this system are located in the heated cell where we find radiators and a convective radiator installed along with the radiant slab. All the HVAC systems attached to the test facility are presented in Figure 1b. The test-cell facility is monitored by a number of sensors that are depicted in table 1 .

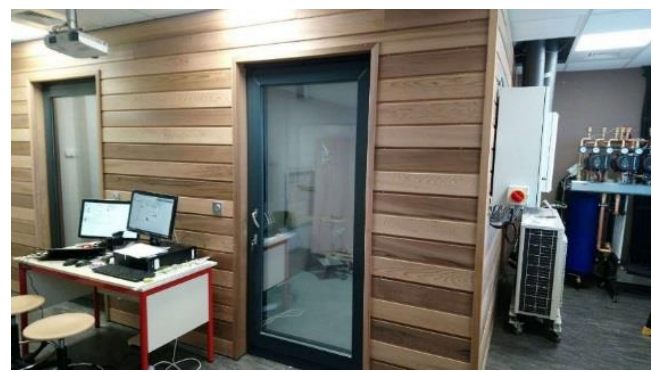

(a)

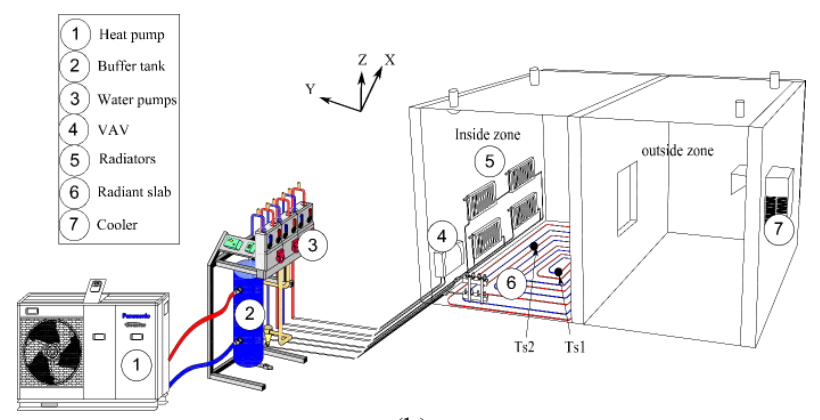

(b)

Fig. 1. Experimental set up. (a) outside view; (b) Overall view.

Data collection from measurement was performed each five minutes thanks to the acquisition system and could be visualized over extended periods. Measurements concern namely average indoor air temperature $(\mathrm{Ta})$ and its relative humidity $(\mathrm{RH})$, mean radiant temperature $\left(T_{\text {rad }}^{\text {meas }}\right.$ ), inlet and outlet water temperatures (Tin and Tout), respectively, average surface temperatures (Ts) with regards to the local surface temperatures and the total heat flux rate $(\phi)$ emitted by the radiant slab.

Table 2. Measured parameters, sensors and equipment characteristics.

\begin{tabular}{|c|c|c|}
\hline Measured parameter & Number & Range \\
\hline $\begin{array}{l}\text { outdoor } \mathrm{RH} \text { and air } \\
\text { temperature } \\
\text { sensor }\end{array}$ & 1 & $\begin{array}{c}{[-50,50]{ }^{\circ} \mathrm{C}} \\
{[0,100] \%}\end{array}$ \\
\hline Indoor RH and air & 1 & {$[-50,50]^{\circ} \mathrm{C}$} \\
\hline Surface temperature & 2 & {$[-20,100]^{\circ} \mathrm{C}$} \\
\hline Depth temperature & 2 & {$[-20,100]{ }^{\circ} \mathrm{C}$} \\
\hline Mean radiant temperature & 1 & {$[-30,75]^{\circ} \mathrm{C}$} \\
\hline Inlet and outlet water & 2 & {$[-20,80]^{\circ} \mathrm{C}$} \\
\hline Infrared thermal camera & 1 & {$[-20,150]{ }^{\circ} \mathrm{C}$} \\
\hline Surface heat flux meter & 2 & $\begin{array}{c}{[-260,260] \mathrm{mV},} \\
<120^{\circ} \mathrm{C}\end{array}$ \\
\hline $\begin{array}{c}\text { Indoor } \mathrm{RH} \text { and ambient } \\
\text { air temperature } \\
\text { sensor }\end{array}$ & 1 & $\begin{array}{c}{[-50,50]^{\circ} \mathrm{C}} \\
{[0,100] \%}\end{array}$ \\
\hline
\end{tabular}

\section{Transient simplified semi-analytical modelling}

As a heat exchanger, the FHS is considered as a waterbased system that emits heat from water to ambient air and the surroundings with a quasi-logarithmic thermal response. Therefore, its transient thermal behaviour may be expresses using Pierson and Padet approach [Pierson, 1988], as follows:

$T_{S}(t)= \begin{cases}T_{s, 0} & t<t_{d} \\ T_{s, \infty}+\left(T_{s, 0}-T_{s, \infty}\right) e^{-\frac{\left(t-t_{d}\right)}{\tau}} & t \geq t_{d}\end{cases}$

where $T_{s, 0}$ is the initial condition of average surface temperature; $T_{s, \infty}$ is the average surface temperature at the equilibrium ; $\tau$ is the time constant; and $t_{d}$ is the delay time. The values of $\tau$ and $t_{d}$ will be determined using the DoE method based on the validated 2D FDM numerical model.

If we can consider the entire heat exchange between the hot water and the ambient air in the inside zone. $\mathrm{T}_{\mathrm{s}, \infty}$ can be calculated based on the heat energy balance as follows:

$T_{s, \infty}=\frac{\left(\overline{T_{f}}-T_{a}\right)}{R_{a}+R_{\text {conv } f}+R_{p}+R_{\text {cond }}} R_{a}+T_{a}$

and the heat flux rate between the hot water and the cold environment can be estimated using the logarithmic mean temperature difference: 


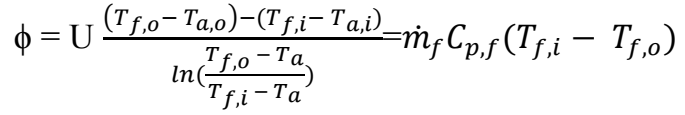

where $U=\frac{1}{\sum_{n} R_{n}}$ is the total heat transfer coefficient (from the hot water to the ambient air); $T_{f, i}$ and $T_{f, o}$ are the inlet and the outlet hot water temperatures, respectively; $T_{a, i}$ and $T_{a, o}$ are the ambient air temperatures at $x=0$ and $L$, respectively, both assumed equal to $T_{a}$ because of the high air volume; $\dot{m}_{f}$ is the water mass flowrate; and $C_{p, f}$ is the water specific heat.

From the last equation, the outlet temperature of the hot water is the following:

$T_{f, o}=T_{a}+\left(T_{f, i}-T_{a}\right) e^{-\frac{U S}{\dot{m}_{f} C} C_{p, f}}$

The temperature $T_{x}$ of the water at position $\mathrm{x}$ of the pipe is given by:

$T_{x}=T_{a}+\left(T_{f, i}-T_{a}\right) e^{-\frac{U_{x} S_{x}}{\dot{m}_{f} C_{p, f}}}$

where $U_{x}$ and $\mathrm{Sx}$ are the overall heat transfer coefficient and heat exchange surface at position $x$ of the pipe.

As a final point, integration of $T_{x}$ over the total length of the tube $L$ yields the average temperature of the hot water $\overline{T_{f}}$ :

$\overline{T_{f}}=\frac{1}{L} \int_{0}^{L} T_{x} \mathrm{dx}=T_{a}+\left(T_{f, i}-T_{a}\left(\frac{1-e^{-\zeta}}{\zeta}\right)\right.$

where $\zeta=\frac{U S}{\dot{m}_{f} C_{p, f}}$.

Design of experiments (DoE) is a systematic and rigorous approach to engineering problem-solving that applies principles and techniques, at the data collection stage, so as to ensure the generation of valid, defensible, and supportable engineering conclusions. The benefit of using the DoE method is the provision of polynomial statistical meta-models with correlation factors and factor interactions for all responses [15]. In the present case study, the response factors are time constant $\tau$ and the delay time $t_{d}$, and the test will be conducted using a validated 2D FDM numerical model. In previous studies [8], both 2D FDM and 3D FVM models were developed and experimentally validated regarding the given experimental scenario to estimate the radiant floor surface temperature and the heat flowrate under transient conditions. The FDM model will be used hereafter to derive meta-models.

Numerous factors influencing $\tau$ and $t_{d}$ need to be considered: those related to the ambient air properties; the anhydrite slab thermo-physical properties; the thermophysical properties of the hot water; and the geometric parameters. To simplify the process, a number of assumptions have been made as mentioned in [Merabtine, 2018]. The ambient air temperature was set between 16 ${ }^{\circ} \mathrm{C}$ and $28{ }^{\circ} \mathrm{C}$. We assumed that all thermo-physical properties remain essentially constant in this temperature range and, as a result, the heat transfer coefficients are kept constant. Similarly, the hot water temperature was set between $27.5^{\circ} \mathrm{C}$ and $31.5^{\circ} \mathrm{C}$ for the given experimental scenarios. Table 2 presents the range variation of the remaining parameters based on the recommendations of the French standard union AFNOR as recognized by the Centre of Scientific and Technical Building Studies.

Table 2. Variations of FHS factors influencing $\tau$ and $t_{d}$

\begin{tabular}{|c|c|c|c|}
\hline \multirow{2}{*}{$\begin{array}{c}\text { Factors } \\
\text { influencing } \tau \\
\text { and } t_{d}\end{array}$} & \multirow{2}{*}{ Labels } & \multicolumn{2}{|c|}{ Levels } \\
\hline & & $\min (-1)$ & $\max (+1)$ \\
\hline $\begin{array}{l}\text { Slab thickness, } \\
\text { e (m) }\end{array}$ & A & 0.04 & 0.06 \\
\hline $\begin{array}{c}\text { Thermal } \\
\text { conductivity of } \\
\text { the slab, } \lambda \\
\left(\mathrm{W} \cdot \mathrm{m}^{-1} \cdot \mathrm{K}^{-1}\right)\end{array}$ & B & 1.2 & 2.6 \\
\hline $\begin{array}{l}\text { Slab density, } \boldsymbol{\rho} \\
\left(\mathrm{kg} \cdot \mathrm{m}^{-3}\right)\end{array}$ & $\mathrm{C}$ & 1500 & 2500 \\
\hline $\begin{array}{c}\text { Specific heat of } \\
\text { the slab, } \boldsymbol{C}_{\boldsymbol{p}} \\
\left(\mathrm{J} \cdot \mathrm{kg}^{-1} \cdot \mathrm{K}^{-1}\right)\end{array}$ & D & 1000 & 2000 \\
\hline $\begin{array}{l}\text { Volume flow } \\
\text { rate, } \dot{\boldsymbol{V}}\left(\mathrm{L}^{-\mathrm{s}^{-1}}\right)\end{array}$ & $\mathrm{E}$ & 0.02 & 0.06 \\
\hline $\begin{array}{l}\text { Tube inner } \\
\text { diameter, } \boldsymbol{D}_{\boldsymbol{i}} \\
(\mathrm{m})\end{array}$ & $\mathrm{F}$ & 0.012 & 0.02 \\
\hline
\end{tabular}

A full factorial metamodeling plan was used to provide all the required data from the DoE. As a result, $2^{6}=64$ simulations, including all interactions between the six parameters listed in table 2, were performed. The metamodels of $\tau$ and $t_{d}$ obtained by the full factorial plan are as follow:

$$
\begin{aligned}
& \tau=(22.16-98 e-1.34 \lambda+0.00006 \rho+ \\
& 0.0016 C p-23.3 \dot{V}+1257 D i+ \\
& 0.37 e \rho+0.47 e C p-15465 e D i+0.000008 \rho C p- \\
& 0.76 \rho D i-1.02 C p D i)^{2} \\
& t_{d}=1532+6586 e+342 \lambda- \\
& 0.0745 \rho-0.0543 C p+3109 \dot{V}+5390 D i- \\
& 6936 e \lambda+5.14 e \rho+8.88 e C p+7533 \lambda D i- \\
& 9.02 C p D i-366133 \dot{V} D i
\end{aligned}
$$


The comparison between the measured and the calculated response factors are presented in Table 3.

Table 3. Calculated and measured time constant and delay time.

\begin{tabular}{|c|c|c|c|}
\hline Parameter & $\begin{array}{c}\text { Measurements } \\
(\mathbf{s})\end{array}$ & $\begin{array}{c}\text { Meta- } \\
\text { model } \\
(\mathbf{s})\end{array}$ & $\begin{array}{c}\text { Relative } \\
\text { deviation } \\
(\%)\end{array}$ \\
\hline $\begin{array}{c}\text { Time } \\
\text { constant } \boldsymbol{\tau}\end{array}$ & 9353 & 9188 & $1.76 \%$ \\
\hline $\begin{array}{c}\text { Delay time } \\
\boldsymbol{t}_{\boldsymbol{d}}\end{array}$ & 503 & 527 & $4.77 \%$ \\
\hline
\end{tabular}

In Figure 2, analytical transient average surface temperature is compared to the numerical and experimental ones. One can see the good agreement with the experimental data, as the maximum error is $1.1{ }^{\circ} \mathrm{C}$ (4\%). Such deviation is mainly due to assumption of logarithmic profile. However, given the simplicity of the model, which represents a significant advantage when looking for fast and reliable results, it can be considered as a useful tool for the estimation and analysis of the thermal behaviour of a radiant slab.

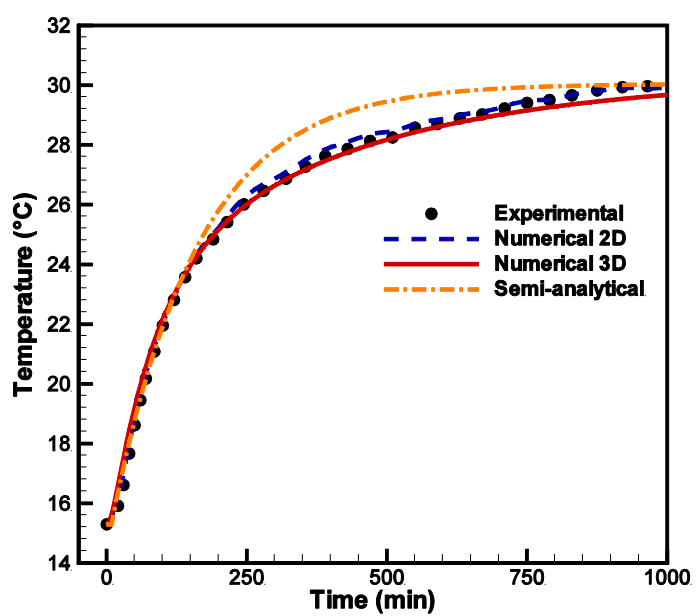

Fig. 2. Experimental, numerical and analytical average surface temperature.

\section{Conclusion}

In this study, a new simplified semi-analytical model, based on a numerical-analytical approach with a constant and delay times is developed and validated to investigate the transient thermal behavior of an experimental floor heating system. The simplified semi-analytical model showed a good accordance with experimental data.

\section{Acknowledgement}

This work was supported by Grand-Est Region, Troyes Champagne Métropole, European Regional Development Fund, and EPF Foundation.

\section{References}

1. B. W. Olesen, ASHRAE J. 44, 19 (2002).

2. Z. Wang, M. Song, F. Wang, Z. Ma, and Q. Lin, Energy Build. 179, 200 (2018).

3. A. Merabtine, R. Benelmir, and M. El Ganaoui, Therm. Sci. 17, 723 (2013).

4. A. J. Werner-Juszczuk, Energy Build. 177, 23 (2018)

5. D. Zhang, N. Cai, and Z. Wang, Energy Build. 61, 260 (2013).

6. A. K. Athienitis, Sol. Energy 61, 337 (1997).

7. A. Merabtine, S. Mokraoui, A. Kheiri, A. Dars, and A. A. Hawila, Energy Build. 174, 619 (2018).

8. M. S. Shin, K. N. Rhee, S. R. Ryu, M. S. Yeo, and K. W. Kim, Build. Environ. 92, 559 (2015).

9. M. Tahersima and P. Tikalsky, Constr. Build. Mater. 178, 360 (2018).

10. S. Thomas, P.-Y. Franck, and P. André, in Build. Simul. (2011).

11. F. De Monte, Int. J. Heat Mass Transf. 43, 3607 (2000).

12. R. Holopainen, P. Tuomaala, and J. Piippo, Energy Build. 39, 1107 (2007).

13. X. Jin, X. Zhang, and Y. Luo, Energy Build. 42, 1753 (2010).

14. M. Koschenz and B. Lehmann, Thermoaktive BauteilsystemeTabs,EMPA Energie systeme/ Haus technik, Zurich (2000).

15. N. Khanna, in Des. Exp. Prod. Eng. (2016). 